О ВЛИЯНИИ РЕГИОНАЛЬНОЙ СПЕЦИФИКИ НА СОДЕРЖАНИЕ АДМИНИСТРАТИВНО-ПРАВОВОГО СТАТУСА ТАМОЖЕННОГО ПОСТА

\author{
А.С. ЖАБОРОВСКИЙ, Д.П. ЛУНЁВ \\ Омский государственный университет им Ф.М. Достоевского, г. Омск
}

\begin{abstract}
В статье рассмотрены вопросы определения административно-правового статуса таможенного поста, проведен сравнительный анализ соотношения полномочий и функций (обязанностей), присущих таможенному посту с учетом наличия региональных факторов. Соответственно предметом работы являлся административноправовой статус таможенного поста, а целью - выявление основных закономерностей, характеризующих административно-правовой статус таможенного поста на современном этапе. В ходе работы проведен сравнительный анализ нормативных правовых актов, позволивший установить основные элементы административноправового статуса таможенного поста, выделить и подчеркнуть его место в системе таможенных органов. В результате были выявлены некоторые закономерности, позволяющие охарактеризовать административно-правовой статус таможенного поста, которые могут быть использованы в ходе дальнейшего уточнения правовой регламентации статуса. Так, отмечено, что в настоящее время таможенный пост обладает самостоятельным статусом, как в области деятельности, так и в принятии решений. Присущий ему набор полномочий в целом является достаточным для полноценного исполнения функций (обязанностей) и отражает место таможенного поста в системе таможенных органов Российской Федерации. Вместе с тем, действующий административно-правовой статус таможенного поста нельзя признать полным, в частности, совершенно не учтены возможности региональных различий в содержании и направлениях их деятельности. В ходе практической деятельности таможенного поста реализуется таможенная политика государства в конкретном регионе - регионе деятельности таможенного поста. Однако, деятельность по определению правового статуса таможенного поста нельзя считать завершенной, что особенно проявляется в отсутствии учета региональных различий в специфике деятельности таможенных постов, следовательно она должна быть продолжена.

Ключевые слова: таможенные органы; таможенный пост; правовой статус; таможенная деятельность; полномочия таможенных органов; функции таможенных органов.
\end{abstract}

Построение функционирующей системы эффективно работающих органов государственной власти по-прежнему ${ }^{1}$ остается одним из наиболее актуальных вопросов. Множественность функций, реализуемых отраслевыми органами государственной вла-

\footnotetext{
1 «Проверяющих органов так много, что если каждый из них хоть один раз придет - все, можно любую фирму закрывать.» - из Послания Президента Российской Федерации В.В. Путина Федеральному Собранию от 4 декабря 2014 г.; публикация на сайте http://www.kremlin.ru/events/preside nt/news/47173 «Уж сколько мы говорим на этот счет, все сокращаем и сокращаем эти полномочия. Где-то сокращаем, они где-то опять вырастают. Целая армия контролеров по-прежнему мешает работать добросовестному бизнесу.» - из Послания Президента Российской Федерации В.В. Путина Федеральному Собранию от 3 декабря 2015 г. «Российская газета», № 275, 04.12.2015
}

сти, предопределила необходимость построения элементной структуры системы исполнительной власти, как с учетом сбалансированного соотношения статуса каждого вида органов власти, так и оптимального распределения компетенций в рамках каждого из них, в т.ч. с учетом региональных особенностей.

В рамках системы таможенных органов, каждый из четырех уровней системы: федеральный орган исполнительной власти, уполномоченный в области таможенного дела - региональные таможенные управления таможни - таможенные посты, отличается от других правовым статусом, компетенцией и прочими элементами, характеризующими государственный орган.

Таможенный пост неотъемлемый, самостоятельный и обладающий уникальным 
административно-правовым статусом элемент системы таможенных органов, который можно рассматривать как базовый элемент, первичное звено этой системы. Мы намерено не рассматриваем вопрос о том, как необходимо рассматривать таможенный пост - в качестве структурного подразделения таможни или же нет, т.к. он является дискуссионным и прямого отношения к теме настоящего исследования не имеет [1]. Вместе с тем, мы будем исходить из того, что таможенный пост является самостоятельным звеном системы таможенных органов, что прямо определено положениями статьи 10 Федерального закона от 27 ноября 2010 г. № 311 Ф3 «О таможенном регулировании в Российской Федерации».

По нашему мнению, по степени плотности и глубины непосредственного взаимодействия с участниками внешней торговли таможенный пост выполняет наибольший объем таможенных операций самого разнообразного направления. Поэтому влияние деятельности таможенного поста на количественные и качественные показатели развития региональной внешней торговли нельзя не учитывать и следует считать весьма важным, а поэтому подлежащим объективному изучению.

Почему еще таможенный пост, как элемент системы таможенных органов, его деятельность и правовой статус в настоящее время могут вызывать повышенный интерес?

Стоит начать с того, что система таможенных органов включает 480 таможенный постов, входящих в состав таможен, подчиняющихся региональным таможенным управлениям, а также 70 таможенных постов, входящих в структуру таможен, непосредственно подчиняющихся ФТС России. Естественно, что это немалое количество таможенных постов распределено по всей территории государства, причем неравномерно. Взаимодействуя с участниками внешнеэкономической деятельности в условиях региональной специфики внешней торговли, определяемой характеристиками региональной экономики, таможенные посты не могут не являться проводниками таможенной политики.

Кроме того, нам кажется, что наличествует ряд причин, как внешнего характера, связанных с созданием и развитием Таможенного союза, постепенным внедрением элементов концепции сервисного государства и снижением объема контрольно-надзорных функций и общим сокращением чис- ленности государственных служащих, так и внутренних, кроющиеся в планомерном развитии таможенного дела и таможенных технологий, в частности:

- совершенствование технических возможностей таможенных органов в области таможенного контроля;

- внедрение передовых таможенных технологий, снижающих степень влияния должностных лиц на принятие решений и сокращающих время контроля;

- перераспределение функциональной нагрузки внутри системы таможенных органов;

- изменение территориальной структуры таможенных органов.

В настоящее время осуществляется эволюционное преобразование структуры таможенных постов, что обусловлено реализацией дорожной карты «Совершенствование таможенного администрирования» и Стратегией развития таможенных органов до 2020 г. Основные направления данной деятельности:

- сокращение количества таможенных постов за счет ликвидации малозагруженных постов [2];

- изменение места нахождения таможенных постов и функционального содержания их деятельности [3];

- преобразование таможен в таможенные посты [4];

- создание системы таможенных постов - центров электронного декларирования, как путем преобразования ранее функционировавших таможенных постов, так и созданием новых постов [5];

- создание новых таможенных постов на участках наибольшей загруженности [6].

Указанные обстоятельства представляются важными, т.к. непосредственно влияют на структуру системы таможенных постов и их функциональную нагрузку, при этом они, во-первых, отражают изменения, происходящие во внешнеэкономической деятельности того или иного региона, во-вторых, предопределяют перспективу таких изменений. Положительным представляется тот факт, что данные факторы, влияющие на региональную экономику, учитываются при принятии решений о ликвидации таможенных постов, которое не может произойти без изучения мнения бизнес-сообщества[7].

Вместе с тем, все происходящие преобразования не затрагивают коренным образом изменений в правовом статусе таможен- 
ного поста, которые, как нам кажется, объективно необходимы.

Определить место таможенного поста в системе таможенных органов и его значение в реализации таможенного дела можно, рассмотрев его деятельность в качестве субъекта таможенных правоотношений, являющихся по сути административно-властными.

В отличие от обычного содержания понятия «правовой статус», включающего права, обязанности и ответственность соответствующего субъекта, статус органа власти обычно характеризуется сочетанием прав и полномочий.

Так, положения обо всех федеральных службах содержат только три раздела: общие положения, полномочия и организацию деятельности. В раздел «полномочия» включен блок о правах службы, также могут содержаться подразделы о контрольных, надзорных регистрационных и иных властных функциях, в зависимости от содержания функциональных направлений деятельности. Объединяющим признаком является отсутствие четкого выделения обязанностей государственного органа. Такая особенность статуса государственных органов отмечена российскими исследователями данного вопроса [8]. Так, И.А. Богданова указывает на то, что правовой статус органов исполнительной власти характеризуется функциями, положением в системе органов государственной власти и местного самоуправления, а также компетенцией и совокупностью полномочий [9].

Однако, статья 12 Федерального закона от 27 ноября 2010 г. № 311-Ф3 «О таможенном регулировании в Российской Федерации» определяет функции (обязанности), которые выполняют таможенные органы. И в этом смысле, определение административноправового статуса таможенного поста, определение его места в системе таможенных органов и обоснование его значения в деятельности таможенных органов можно осуществить, проведя анализ полномочий в сопоставлении с функциями (обязанностями) таможенных органов.

С учетом того, что полномочия напрямую связаны с реализацией органом государственной власти, его функций и проявляются одновременно, и как обязанность, и как право, нам представляется, что данный подход позволит прийти к объективным выводам по рассматриваемому вопросу.
В настоящее время полномочия таможенного поста определены Общим положением о таможенном посте, утвержденным приказом ФТС России от 4 сентября 2014 г. № 1701, на их анализе мы и сосредоточимся. Следует указать, что некоторые таможенные посты, решающие специализированные задачи, действуют на основании индивидуальных положений [10].

Итак, приводим сравнительный анализ соответствия функциям (обязанностям) таможенных органов, включенных в статью 12 Федерального закона «О таможенном регулировании», полномочий таможенного поста:

1) Проводят таможенный контроль, совершенствуют методы совершения таможенных операций и проведения таможенного контроля, создают условия, способствующие ускорению товарооборота при ввозе товаров в Российскую Федерацию и вывозе товаров из Российской Федерации. Анализ Общего положения о таможенном посте позволяет отнести к реализации этой функции полномочия, определенные в следующих подпунктах пункта 5: 1, 2, 3, 4, 7, 8, 9, 10, 11, 12, 13, $14,15,16,17,18,19,41,42,43,46,47,65^{2}$.

2) Содействуют развитию внешней торговли Российской Федерации, внешнеэкономических связей субъектов Российской Федерации, ускорению товарооборота. Данной обязанности соответствуют положения подпункта 43 в части, касающейся создания условий по ускорению товарооборота.

3) Ведут таможенную статистику внешней торговли и специальную таможенную статистику. К реализации этой функции (обязанности) можно отнести следующие подпункты пункта 5 Общего положения: 36, 73, 74.

4) Взимают таможенные пошлины, налоги, антидемпинговые, специальные и компенсационные пошлины, таможенные сборы, контролируют правильность исчисления и своевременность уплаты указанных пошлин, налогов и сборов, принимают меры по их принудительному взысканию. Такая функция (обязанность) реализуется следующими полномочиями, указанными в подпунктах 6,42 , 49, 50, 51, 52, 53.

5) Обеспечивают на территории Российской Федерации соблюдение порядка перемещения товаров и транспортных средств

\footnotetext{
2 здесь и далее приводятся номера подпунктов пункта 5 Общего положения о таможенном посте, определяющих конкретные полномочия таможенного поста
} 
международной перевозки через таможенную границу Таможенного союза. Как ни удивительно, но в перечне полномочий таможенного поста нет ни одного, прямо относящегося к данной функции (обязанности). При этом установлено право таможенного поста останавливать автомобильные транспортные средства, в том числе не осуществляющие международные перевозки товаров, если на указанных автомобильных транспортных средствах перевозятся товары, находящиеся под таможенным контролем, в целях проверки соблюдения таможенного законодательства Таможенного союза и законодательства Российской Федерации о таможенном деле для осуществления проверки товаров и документов на них.

6) Обеспечивают, если иное не установлено законодательством Российской Федерации, соблюдение установленных в соответствии с международными договорами государств - членов Таможенного союза и законодательством Российской Федерации запретов и ограничений в отношении товаров, ввозимых в Российскую Федерацию и вывозимых из Российской Федерации. Данной функции соответствует полномочие, указанное в подпункте 42, которые мы также отнесли к 1-ой и 4-ой обязанностям.

7) Обеспечивают в пределах своей компетенции защиту прав на объекты интеллектуальной собственности. Из пункта 5 Общего положения мы можем взять подпункт 5: обеспечение защиты прав интеллектуальной собственности на таможенной территории Таможенного союза в соответствии с установленным порядком.

8) Выявляют, предупреждают, пресекают преступления и административные правонарушения, отнесенные законодательством Российской Федерации к компетенции таможенных органов, а также иные связанные с ними преступления и правонарушения, проводят неотложные следственные действия и осуществляют предварительное расследование в форме дознания по уголовным делам об указанных преступлениях, осуществляют административное производство по делам об административных правонарушениях в области таможенного дела (о нарушениях таможенных правил), оказывают содействие в борьбе с коррупцией и международным терроризмом, осуществляют противодействие незаконному обороту объектов интеллектуальной собственности, наркотических средств, психотропных веществ, оружия и боеприпасов, культурных ценностей и иных предметов, перемещаемых через таможенную границу Таможенного союза и (или) через Государственную границу Российской Федерации. Данной, широкой по содержанию функции (обязанности), соответствуют, на наш взгляд подпункты $23,24,25,26,27$, 28, 29, 30, 31 пункта 5 Общего положения.

9) Содействуют осуществлению мер по защите государственной безопасности, общественного порядка, нравственности населения, жизни и здоровья человека, животных и растений, охране окружающей природной среды, защите интересов потребителей товаров, ввозимых в Российскую Федерацию. Из пункта 5 Общего положения можно частично отнести подпункт 44: обеспечение в пределах своей компетенции мер по защите национальной безопасности государств - членов Таможенного союза, жизни и здоровья человека, животного и растительного мира, окружающей среды, а кроме того подпункты 54 и 55.

10) Осуществляют в пределах своей компетенции контроль за валютными операциями, связанными с перемещением товаров через таможенную границу Таможенного союза, а также с ввозом товаров в Российскую Федерацию и их вывозом из Российской Федерации, в соответствии с международными договорами государств - членов Таможенного союза, валютным законодательством Российской Федерации и принятыми в соответствии с ним нормативными правовыми актами органов валютного регулирования. Этой функции (обязанности), по нашему мнению, соответствуют полномочия. Предусмотренные подпунктами 16 и 44 пункта 5 Общего положения о таможенном посте.

11) Содействуют развитию экспортного и транзитного потенциала Российской Федерации, оптимизации структуры экспорта, защищают с использованием средств таможенного регулирования интересы отечественных товаропроизводителей, постоянно совершенствуют систему таможенного контроля, способствующую оптимальному использованию ресурсов таможенных органов. Данная функция (обязанность), исходя из содержания, кажется не совсем относящейся к деятельности таможенного поста, тем не менее, полномочия, определенные подпунктами 48 и 62 пункта 5 Общего положения о таможенном посте, представляются прямым её воплощением. 
12) Обеспечивают в соответствии с международным договором государств - членов Таможенного союза меры по противодействию легализации (отмыванию) доходов, полученных преступным путем, и финансированию терроризма при осуществлении контроля за перемещением через таможенную границу Таможенного союза валюты государств - членов Таможенного союза, ценных бумаг и (или) валютных ценностей, дорожных чеков. К данной функции (обязанности) таможенных органов мы вправе отнести предусмотренные подпунктом 44 полномочия: обеспечение в пределах своей компетенции, а также в соответствии с международным договором государств - членов Таможенного союза мер по противодействию легализации (отмыванию) доходов, полученных преступным путем, и финансированию терроризма при осуществлении контроля за перемещением через таможенную границу Таможенного союза валюты государств - членов Таможенного союза, ценных бумаг и (или) валютных ценностей, дорожных чеков.

13) Разъясняют заинтересованным лицам их права и обязанности в области таможенных правоотношений, оказывают содействие в пределах своих полномочий участникам внешнеэкономической деятельности в реализации ими своих прав при совершении таможенных операций в отношении товаров и транспортных средств международной перевозки. К реализации данной функции (обязанности), как нам представляется, относятся полномочия, установленные подпунктами $32,33,34,35$, и частично 43 : «обеспечение в пределах своей компетенции соблюдения прав и законных интересов лиц в области таможенного регулирования».

14) Обеспечивают выполнение международных обязательств Российской Федерации в части, касающейся таможенного дела, осуществляют сотрудничество с таможенными и иными компетентными органами иностранных государств, международными организациями, занимающимися вопросами таможенного дела. Мы затруднились с выделением конкретных полномочий, прямо связанных с реализацией вышеуказанной функции (обязанности).

15) Осуществляют информирование и консультирование в области таможенного дела, обеспечивают в установленном порядке государственные органы, организации и граждан информацией по вопросам таможенного дела. Из пункта 5 Общего положения о таможенном посте мы можем указать только подпункт 20.

16) Проводят научно-исследовательские и опытно-конструкторские разработки в области таможенного дела. Такая функция (обязанность) также, по нашему мнению, не нашла своего отражения в полномочиях таможенного поста.

Кроме того, в соответствии с частью 2 статьи 12 Федерального закона установлено, что федеральными законами на таможенные органы могут быть возложены иные функции (обязанности).

К таковым мы полагаем возможным отнести полномочия, определенные подпунктами 45 и 75.

Проведенный анализ позволил установить целый блок полномочий, указанных в Общем положении о таможенном посте, прямо не относящихся к какой либо из функций (обязанностей). В частности они указаны в подпунктах: 21, 22, 37-40, 56-61, 63, 64, 66-72, 76.

Их содержательный анализ позволяет установить, что все они направлены на обеспечение нормального функционирования таможенного поста в разных сферах, к примеру, правового обеспечения, информационно-технического обеспечения, соблюдения служебной дисциплины, исполнительской дисциплины и документационного обеспечения, материально-технического обеспечения, обеспечения охраны труда и т.д. При этом, наличие целого комплекса полномочий, направленных на обеспечение нормального функционирования таможенного поста, подчеркивает самостоятельный характер деятельности данного таможенного органа и особое место в организационной структуре таможенных органов.

Проведенный анализ и сопоставление функций (обязанностей) таможенных органов и полномочий таможенного поста позволяет сделать следующие выводы:

1. В настоящее время административноправовой статус таможенного поста вполне определен, функционально содержателен и достаточно полно сочетает большой круг вопросов ведения таможенного поста с необходимыми полномочиями.

2. Не все функции (обязанности) таможенных органов нашли свое отражение в полномочиях таможенного поста. По всей видимости, это и есть иллюстрация того места, которое таможенный пост занимает в системе таможенных органов. Наибольшая часть 
полномочий таможенного поста связана с непосредственным осуществлением таможенного контроля, взиманием таможенных платежей, выявлением и пресечением противоправных деяний в области таможенного дела.

3. Весь комплекс полномочий таможенного поста неравномерно распределен между функциями (обязанностями) таможенных органов, реализуемых таможенным постом непосредственно. Некоторые функции (обязанности) таможенных органов представлены полным и объемным набором полномочий, другие же отражены номинально и декларативно, либо вовсе не нашли своего отражения. Данное обстоятельство также демонстрирует место, занимаемое таможенным постом в системе таможенных органов.

4. Некоторые полномочия поста напрямую не связаны с реализацией функций (обязанностей) таможенных органов. Как правило, они относятся к деятельности, обеспечивающей функционирование таможенного поста.

5. Ни функции (обязанности), ни полномочия, присущие таможенному посту, не определяют конкретные механизмы их реализации, не влияют прямо на структуру таможенного поста, его специализацию, компетенцию и другие параметры, характеризующие деятельность конкретного таможенного поста. Таким образом, для каждого конкретного таможенного поста набор полномочий, реализуемых практической деятельностью, будет определяться местом расположения, структурой внешней торговли в регионе деятельности, инфраструктурой мест совершения таможенных операций и проведения таможенного контроля и другими факторами, т.е. региональными факторами.

6. Некоторые функции (обязанности) таможенных органов, на практике реализуемые таможенными постами, не включены в перечень их полномочий.

7. В нормативно определенном административно-правовом статусе таможенного поста совершенно не учтены возможности региональных различий в содержании и направлениях их деятельности. Данное обстоятельство порождает ситуацию, когда ФТС России может своими решениями ограничивать полномочия или компетенцию конкретных таможенных постов, в т.ч., к сожалению, по субъективным конъюнктурным мотивам.

С учетом вышеизложенного, можно отметить, что в настоящее время таможенный пост в системе таможенных органов занимает вполне определенное и особое место, обладая самостоятельным статусом, как в области деятельности, так и в принятии решений. Присущий ему набор полномочий в целом является достаточным для полноценного исполнения функций (обязанностей). В ходе практической деятельности таможенного поста реализуется таможенная политика государства в конкретном регионе - регионе деятельности таможенного поста. Вместе с тем деятельность по определению правового статуса таможенного поста нельзя считать завершенной, что особенно проявляется в отсутствии учета региональных различий в специфике деятельности таможенных постов.

\section{Литература}

1. Трунина, Е.В. Актуальные вопросы административно-процессуального статуса таможенных органов // Административное право и процесс. 2012. № 6. С. $41-44$.

2. Приказ ФТС России от 07.07.2015 № 1355 «О ликвидации Ленинского таможенного поста Хабаровской таможни, таможенного поста Аэропорт Анадырь Магаданской таможни и внесении изменений в приложение к приказу ФТС России 16 сентября 2013 г. № 1751»

3. Приказ ФТС России от 16.03.2015 № 438 «О Тындинском таможенном посте Благовещенской таможни, об изменении региона деятельности Нерюнгринского таможенного поста Благовещенской таможни и о внесении изменений в приложение к Приказу ФТС России от 16 сентября 2013 г. № 1751», приказ ФТС России от 25.08.2015 № 1730 «О Прокопьевском таможенном посте Кемеровской таможни»

4. Приказ ФТС России от 16.07.2010 № 1352 «О совершенствовании структуры таможенных органов, расположенных в Приволжском федеральном округе»

5. Приказ ФТС России от 03.07.2012 № 1326 «О создании Ярославского таможенного поста (центра электронного декларирования) Ярославской таможни», Приказ ФТС России от 09.11.2012 № 2271 «О переименовании и изменении местонахождения Северского таможенного поста Томской таможни и Черлакского таможенного поста Омской таможни» 
6. Приказ ФТС России от 29.06.2015 № 1283 «О создании таможенного поста Бронка Балтийской таможни»

7. Постановление Правительства Российской Федерации от 20.10.2012 № 1071 «Об утверждении Правил создания, реорганизации и ликвидации региональных таможенных управлений, таможен и таможенных постов»

8. Смирнова, А.А. О соотношении государственных услуг, функций и полномочий органов исполнительной власти // Журнал российского права. 2015. № 3. С. 120 - 130.

9. Богданова, И.А. Система науки конституционного права. М., Юристъ, 2001. С. 56, 64 - 72;

10. Приказ ФТС России от 25.09.2015 № 1947 «Об утверждении Положения о Западном таможенном посте сбора и анализа информации о контроле за доставкой товаров Смоленской таможни и внесении изменений в приказ ГТК России от 9 августа 1995 г. № 492»; Приказ ФТС РФ от 05.07.2007 № 815 «Об утверждении Положения о Северо-Западном акцизном таможенном посте (специализированном)».

Жаборовский Антон Сергеевич - начальник Омского таможенного поста Омской таможни, преподаватель кафедры международных экономических отношений факультета международного бизнеса Омского государственного университета им Ф.М. Достоевского, г. Омск, e-mail: rusanton77@mail.ru.

Лунёв Дмитрий Петрович - главный государственный таможенный инспектор отдела таможенных процедур и таможенного контроля Омской таможни, доцент кафедры государственного и муниципального управления и таможенного дела Омского государственного технического университета, (г. Омск); email:_5577@ mail.ru.

Дата поступления 9 мая 2016 г.

DOI: $10.14529 / \mathrm{iimj} 160305$

\title{
ABOUT THE IMPACT OF REGIONAL SPECIFICS ON CONTENT OF THE ADMINISTRA- TIVE AND LEGAL STATUS OF THE CUSTOMS POST
}

\author{
A.S. ZHABOROVSKIY, D.P. LUNEV \\ Dostoevsky Omsk State University, Omsk
}

The article describes questions which define administrative and legal status of the customs post, and there was performed a comparative analysis of the balance powers and functions (duties) inherent customs post, taking into account the presence of regional factors. For this reason the object of the work was administrative and legal status of the customs post, and the purpose was to identify the main regularities characterizing the administrative and legal status of the customs post at the present stage. In the work a comparative analysis of regulatory legal acts was performed, which allowed to ascertain the basic elements of administrative-legal status of the customs post, to highlight and emphasize its place in the system of customs authorities. The results have identified some regularity that allow to describe the administrative and legal status of the customs post, which can be used in the further clarification of legal regulatory status. So it is noted that nowadays the customs post has an independent status, both in field of activities and in decision making. Its inherent set of powers is generally sufficient for full execution of the functions (duties) and reflects the location of the customs post in the system of customs authorities of the Russian Federation. However, the current administrative and legal status of the customs post cannot be considered comprehensive; in particular possible regional differences and directions of their activities are not taken into account. In the practical activities of the customs post the customs policy of the state in the region of the customs post is implemented. However, the activities to define the legal status of a customs post cannot be considered complete, especially in the absence of regional differences in specificity of activity of customs posts, hence it should be continued.

Keywords: customs authorities; customs post; legal status; customs activity; power of the customs authorities; functions of the customs authorities. 


\section{References}

1. Trunina E. V. Topical issues of administrative and procedural status of customs authorities // Administrative law and process. 2012. No. 6. pp. $41-44$.

2. Order of the FCS of Russia from 07.07.2015 No 1355 "About the liquidation of the Lenin customs post of Khabarovsk customs, a customs post Airport Anadyr Magadan customs and amending the Annex to the order of the FCS of Russia on September 16, 2013 No 1751"

3. Order of the FCS of Russia from 16.03.2015 No 438 "On the Tynda customs post of Blagoveshchensk customs, about the change in the region of the Neryungri customs post of the Annunciation of customs and on amendments in the Annex to the Order of the FCS of Russia from September 16, 2013 № 1751", the order of the FCS of Russia from 25.08.2015 No. 1730 "About Prokop'yevsk customs post of the Kemerovo customs"

4. Order of the FCS of Russia from 16.07.2010 No 1352 "About improvement of structure of customs bodies located in the Volga Federal district"

5. Order of the FCS of Russia from 03.07.2012 No1326 "On the establishment of the Yaroslavl customs post (the electronic Declaration center), the Yaroslavl custom", the Order of the FCS of Russia from 09.11.2012 No 2271 "About renaming and changing the location of Seversk Tomsk customs post of customs and Cherlaksky customs post of the Omsk customs

6. Order of the FCS of Russia from 29.06.2015 No1283 "On a customs post of the Baltic customs Bronka"

7. The resolution of the Government of the Russian Federation dated 20.10.2012 No 1071 "On approval of Rules of creation, reorganization and liquidation of regional customs departments, customs offices and customs posts"

8. Smirnov, A. A. On the ratio of government services, functions and powers of Executive authorities // Journal of Russian law. 2015. No. 3. P. $120-130$.

9. Bogdanov I. A. The System of science of constitutional law. M., Yurist, 2001. P. 56, 64 and 72;

10. Order of the FCS of Russia from 25.09.2015 No. 1947 "About the Position statement about Western customs post collecting and analyzing information about control over the delivery of the goods Smolensk customs and amending order of the SCC of Russia of August 9, 1995, № 492"; the Order of the FCS of the Russian Federation dated 05.07.2007 № 815 "On approval of Regulations on the NorthWestern excise customs post (specialized)".

Zhaborovskiy Anton Sergeevich - the chief of Omsk customs post of the Omsk customs, lecturer of the department of international economic relations of the faculty of international business. Dostoevsky Omsk State University, Omsk, e-mail: rusanton77@mail.ru.

Lunev Dmitriy Petrovich - the chief state customs inspector of Department of customs procedures and customs control of the Omsk customs, the associate professor of the Department of state and municipal administration and customs, Omsk state technical University, Omsk, email:_5577@mail.ru.

Received 9 May 2016

\begin{tabular}{|c|c|}
\hline ОБРАЗЕЦ ЦИТИРОВАНИЯ & FOR CITATION \\
\hline $\begin{array}{l}\text { Жаборовский, А.С. О влиянии регио- } \\
\text { нальной специфики на содержание админи- } \\
\text { стративно-правового статуса таможенного } \\
\text { поста. / А.С. Жаборовский, Д.П. Лунёв // } \\
\text { Журнал Управление инвестициями и инно- } \\
\text { вациями. - 2016. - № 3. C. } 31-38 . \\
\text { DOI:10.14529/iimj160305 }\end{array}$ & $\begin{array}{l}\text { Zhaborovskiy, A.S., Lunev, D.P. About } \\
\text { the impact of regional specifics on content of } \\
\text { the administrative and legal status of the cus- } \\
\text { toms post. Investment and innovation man- } \\
\text { agement journal. - 2016. - No. 3. pp. } 31- \\
\text { 38. } \\
\text { DOI: } 10.14529 \text { /iimj160305 }\end{array}$ \\
\hline
\end{tabular}

